\title{
Lipegfilgrastim in the management of chemotherapy-induced neutropenia of cancer patients
}

This article was published in the following Dove Press journal:

Biologics: Targets and Therapy

22 January 2016

Number of times this article has been viewed

\author{
Roberto Guariglia' \\ Maria Carmen Martorelli' \\ Rosa Lerose ${ }^{2}$ \\ Donatella Telesca ${ }^{2}$ \\ Maria Rita Milella ${ }^{2}$ \\ Pellegrino Musto ${ }^{3}$ \\ 'Unit of Hematology and Stem Cell \\ Transplantation, ${ }^{2}$ Pharmacy Service, \\ ${ }^{3}$ Scientific Direction, IRCCS, Referral \\ Cancer Center of Basilicata, Rionero \\ in Vulture, Potenza, Italy
}

\begin{abstract}
Neutropenia and febrile neutropenia $(\mathrm{FN})$ are frequent and potentially fatal toxicities of myelosuppressive anticancer treatments. The introduction of granulocyte colony-stimulating factors (G-CSFs) in clinical practice has remarkably reduced the duration and severity of neutropenia, as well as the incidence of FN, thus allowing the administration of chemotherapeutic agents at the optimal dose and time with lower risk. The current scenario of G-CSFs in Europe includes filgrastim, lenograstim, some G-CSF biosimilars, and pegfilgrastim. Recently, a novel long-acting G-CSF, lipegfilgrastim, became available. Lipegfilgrastim is a glycopegylated G-CSF, alternative to pegfilgrastim, and has shown in randomized trials, to be equivalent to pegfilgrastim in reducing the incidence of severe neutropenia and $\mathrm{FN}$ in patients with breast cancer receiving chemotherapy, with a similar safety profile. Furthermore, lipegfilgrastim was more effective than the placebo in reducing the incidence of severe neutropenia, its duration, and time to absolute neutrophil count recovery, in patients with non-small cell lung cancer receiving myelosuppressive therapy. Although the number of studies currently published is still limited, lipegfilgrastim seems to be a promising drug in the management of chemotherapyinduced neutropenia.
\end{abstract}

Keywords: neutropenia, febrile neutropenia, granulocyte colony-stimulating factors, G-CSF, pegfilgrastim, lipegfilgrastim

\section{Introduction}

Neutropenia is one of the most frequent and serious complications in cancer patients receiving chemotherapy. Chemotherapy-induced neutropenia (CIN) can lead to febrile neutropenia (FN) which is commonly defined as a fever $>38.5^{\circ} \mathrm{C}$ orally, or two consecutive readings of $>38.0^{\circ} \mathrm{C}$ over a 2 hour period, and an absolute neutrophil count (ANC) $<0.5 \times 10^{9} / \mathrm{L}$, or expected to fall below $0.5 \times 10^{9} / \mathrm{L} \cdot{ }^{1-3} \mathrm{CIN}$ is generally classified according to its severity; the Common Toxicity Criteria of the National Cancer Institute, which is the most used scale in the world for grading chemotherapy-related cytopenias, distinguishes five grades of neutropenia: grade 1 (ANC: $1.5-2.0 \times 10^{9} / \mathrm{L}$ ), grade $2\left(1.0-1.5 \times 10^{9} / \mathrm{L}\right)$, grade $3\left(0.5-1.0 \times 10^{9} / \mathrm{L}\right)$, grade 4 (less than $\left.0.5 \times 10^{9} / \mathrm{L}\right)$, and grade 5 (death). ${ }^{4}$ Because neutrophils are one of the principal mediators of the innate immune system and the first-line of defense to many infective agents, severe neutropenia can lead to life-threatening infection and sepsis. ${ }^{5}$ Indeed, severe CIN and FN are associated with increased risk for infections and related morbidity and mortality in cancer patients receiving myelosuppressive chemotherapy. ${ }^{6,7}$

As observed for other hematological toxicities, CIN and FN are strongly related to the type of chemotherapy. The anti-neoplastic agents and the combination regimens
Correspondence: Roberto Guariglia Unit of Hematology and Stem Cell Transplantation, IRCCS, Centro di Riferimento Oncologico della Basilicata, Via Padre Pio, I, 85028 Rionero in Vulture, Potenza, Italy

Tel +390972 726396

Fax +390972 726217

Email robertoguariglia@libero.it
Dovepress

http://dx.doi.org/1 0.21 47/1BTT.S58597
Biologics: Targets and Therapy 2016:10 I-8

(c) (1) (2) 2016 Guargilia et al. This work is published by Dove Medical Press Limited, and licensed under Creative Commons Attribution - Non Commercial (unported, 33.0)

\section{I}

BY LC License. The full terms of the License are available at http://creativecommons.org/licenses/by-n/3.0/. Non-commercial uses of the work are permitted without any further permission for how to request permission may be found at: http://www.dovepress.com/permissions.php 
are crucial to estimate the risk of FN: chemotherapy regimens that lead to an incidence of FN greater than $20 \%$ is considered at high-risk, whereas an incidence of 10\%-20\% and less than $10 \%$ are considered at intermediate-risk and low-risk, respectively. ${ }^{8,9}$

Chemotherapy combinations, containing anthracycline plus cyclophosphamide, frequently used for the treatment of patients with breast cancer or lymphoma, or anthracycline plus taxane, are associated with high risk of FN. ${ }^{10,11}$

Dose-dense (increased frequency) and dose-intense (increased dose) regimens improve the efficacy of a treatment, but are related to a higher risk to develop severe neutropenia and FN. ${ }^{12,13}$

The risk of FN also depends on patient-related factors. ${ }^{9,14}$ Elderly patients (generally more than 65 years old) are at higher risk for developing severe neutropenia. ${ }^{15,16}$ In addition, previous chemotherapeutic or radiotherapic treatments increase the risk of CIN because of the potentially compromised medullary reserve, as well as the presence of bone marrow metastasis in a solid tumor. Other risk factors for neutropenic complications are poor performance and nutritional status, medical comorbidities including liver and renal dysfunction, and hematological malignancies. ${ }^{17,18}$ Low blood cell count at baseline and previous episodes of FN can also negatively impact on CIN and FN. ${ }^{19}$ Although not yet validated, the models for predicting FN based on the risk factors have also been proposed for patients with hematological cancers and breast cancer. ${ }^{20,21}$

As a consequence of $\mathrm{FN}$, patients could require antibiotic treatment and hospitalization; furthermore, FN could lead to dose reductions and treatment delays that may impact negatively on the efficacy of the planned treatment. ${ }^{7,9,21}$ Indeed, poor outcome due to the modification of the planned chemotherapy regimen has been described in patients with lymphoma, breast cancer, lung cancer, and ovarian cancer. ${ }^{22-24}$

Thus, preventing the occurrence of CIN and FN and their potentially fatal consequences is a clinical priority for patients undergoing anticancer treatments.

\section{Granulocyte colony-stimulating factors}

The introduction of granulocyte colony-stimulating factors (G-CSFs) in the 1980s had a remarkable impact on reducing the duration of $\mathrm{CIN}$ and the incidence of FN by stimulating neutrophil proliferation and differentiation in cancer patients receiving chemotherapy. ${ }^{25}$ In clinical practice, the prophylactic use of G-CSF varies widely in the timing of administration and in choice of patients to treat.
International guidelines recommended the use of G-CSF from the first cycle of chemotherapy (primary prophylaxis) if chemotherapy is associated with a high-risk to develop $\mathrm{FN}$, or in patients who had experienced $\mathrm{FN}$ after a previous cycle of chemotherapy, in which primary prophylaxis had not been administered, and reducing dose intensity is not an appropriate strategy (secondary prophylaxis). G-CSFs are also indicated in subjects with any factor that can increase the overall risk of FN. ${ }^{8,9,26}$

Filgrastim, a recombinant G-CSF (rG-CSF) produced in Escherichia coli, was approved by US Food and Drug Administration in 1991. Multiple randomized trials demonstrated that treatment with filgrastim reduced the incidence of fever and infection, as well as the use of antibiotic/antifungal treatments and hospitalization, in patients receiving myelosuppressive therapy for cancer disease. ${ }^{27,28}$ Filgrastim is also used in patients with congenital or idiopathic neutropenia or for reducing the time of neutropenia recovery following chemotherapy treatment of adults with acute myeloid leukemia.

Lenograstim, a glycosylated rG-CSF derived from Chinese hamster ovary cells, represents a valid alternative to filgrastim in management of neutropenia of patients receiving myeloablative treatments. ${ }^{29}$ Lenograstim is more stable and probably more active than filgrastim on a weight-by-weight basis with regards to in vitro colony-forming and cell assays. ${ }^{30,31}$ However, in a systematic review comparing lenograstim with filgrastim, no reason to prefer lenograstim in any of the approved indications was identified. ${ }^{32}$

Filgrastim and lenograstim are short-acting G-CSFs; they are used by daily subcutaneous injections after each chemotherapy cycle. These G-CSFs are rapidly cleared through the kidney filtration, resulting in a brief circulating half-life.

Both filgrastim and lenograstim are widely administered in the transplant setting, either for mobilization of hematopoietic stem cells out of bone marrow into peripheral blood, replacing bone marrow collection, or as supportive care after autologous or allogenic transplantation. .,33 $^{8,}$

Several filgrastim biosimilars, showing similar effects to the originator G-CSF, have been developed over the years. ${ }^{34}$

\section{Pegfilgrastim}

Pegylation is a process in which polyethylene glycol (PEG) chains are attached to protein drugs, increasing the mass and allowing drug protection from enzyme degradation and rapid renal clearance (Figure 1). ${ }^{35}$

Pegfilgrastim is obtained by a covalent attachment of PEG to the N-terminal methionine residue of filgrastim. 
A

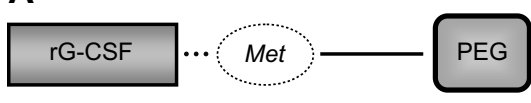

B

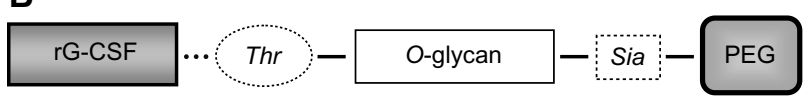

Figure I Schematic structures of pegfilgrastim.

Notes: (A) A recombinant form of G-CSF to which a $20 \mathrm{kDa}$ PEG molecule is covalently bound to the $\mathrm{N}$-terminal methionine residue, and lipegfilgrastim (B), in which a $20 \mathrm{kDa}$ PEG-sialic acid derivative is transferred to a $\mathrm{O}$-glycan moiety bound at the threonine 134 site of $\mathrm{rG}-\mathrm{CSF}$.

Abbreviations: Met, methionine; PEG, polyethylene glycol; rG-CSF, recombinant granulocyte colony-stimulating factor; Sia, sialic acid; Thr, threonine.

Because of the addiction of the PEG, filgrastim significantly reduces its renal clearance and is primarily cleared by neutrophils, creating a self-regulated mechanism of excretion. Pegfilgrastim and filgrastim bind equally to the same G-CSF receptor and have the same mechanism of action, but due to its different pharmacokinetic features, only a single dose of $6 \mathrm{mg}$ of pegfilgrastim is required per cycle. ${ }^{36,37}$

A randomized Phase III trial demonstrated that a single dose of pegfilgrastim was comparable to multiple daily injections of filgrastim in providing neutrophil support after myelosuppressive chemotherapy, and was as safe and well tolerated as filgrastim..$^{38}$ Further studies showed that the efficacy of pegfilgrastim was similar to or greater than filgrastim, with a schedule of administration characterized by a better treatment compliance and improved patient quality of life..$^{39}$

Prophylaxis with pegfilgrastim was also effective and well tolerated in patients with lymphoma receiving chemotherapy, particularly in dose-dense schedules of treatment. ${ }^{40,41}$

Data suggest that, compared with daily G-CSFs, a single dose of pegfilgrastim was at least equal in the mobilization of hematopoietic stem cells as well as in tolerability, marrow recovery, severity of neutropenia, incidence and duration of $\mathrm{FN}$, infections and transfusions following high-dose therapy, and autologous blood stem cell transplantation. ${ }^{42,43}$

\section{Lipegfilgrastim}

Lipegfilgrastim (Lonquex ${ }^{\circledR}$, TEVA Ltd, Petach Tikva, Israel), previously known as XM22, is a new, once-per-cycle, pegylated, recombinant G-CSF, alternative to pegfilgrastim, approved by the European Medicines Agency in July 2013 for reducing the duration of $\mathrm{CIN}$ and the incidence of $\mathrm{FN}$ in cancer patients receiving chemotherapy (with the exception of chronic myeloid leukemia and myelodysplastic syndrome) ${ }^{44}$

Lipegfilgrastim is synthetized using a highly site-specific glycoPEGylation technology, consisting of a conjugation of single 20-kDa PEG to a previously attached glycan moiety and not directly to an amino acid as in standard pegylation of pegfilgrastim (Figure 1). The different structure of lipegfilgrastim results in different pharmacokinetic and pharmacodynamic properties. ${ }^{45-47}$

Based on preclinical studies, G-CSF receptor binding was equivalent between lipegfilgrastim and pegfilgrastim. In addition, lipegfilgrastim showed greater time-dependent resistance to neutrophil elastase degradation and greater retention of activity than pegfilgrastim. This might explain the longer in vivo half-life of lipegfilgrastim compared with pegfilgrastim. ${ }^{48,49}$

Pharmacokinetic and pharmacodynamic properties and safety of lipegfilgrastim were assessed in two Phase I, singleblind, randomized studies conducted in healthy adult subjects, and published in a single paper. ${ }^{50}$

In the first study, two body-weight-adjusted doses of lipegfilgrastim (50 and $100 \mu \mathrm{g} / \mathrm{kg}$ ) or a single body-weightadjusted dose of pegfilgrastim $(100 \mu \mathrm{g} / \mathrm{kg})$, were administered subcutaneously to healthy volunteers.

The second study, based on the pegfilgrastim dose recommended in clinical practice, compared a fixed $6 \mathrm{mg}$ subcutaneous dose of lipegfilgrastim with a $6 \mathrm{mg}$ subcutaneous dose of pegfilgrastim in 36 healthy volunteers.

After body-weight-adjusted and fixed doses, cumulative exposure $\left(\mathrm{AUC}_{0 \text {-tlast }}\right.$ and $\left.\mathrm{AUC}_{0-\infty}\right)$ and peak exposure $\left(C_{\max }\right)$ were higher for lipegfilgrastim than pegfilgrastim. In both studies, the terminal elimination half-life of lipegfilgrastim was 5-10 hours longer than the terminal elimination half-life for pegfilgrastim at the maximum dose; similarly, the time to maximum serum concentration $\left(t_{\max }\right)$ was measured later for lipegfilgrastim than pegfilgrastim. Furthermore, in both studies, the area over the baseline effect curve for ANC was approximately $30 \%$ higher with lipegfilgrastim than with pegfilgrastim, whereas $\mathrm{ANC}_{\max }$ were similar for the same dose of the two drugs. The discrepancy between ANC area over the baseline effect curve and $\mathrm{ANC}_{\max }$ was likely due to the longer duration of action of lipegfilgrastim as a result of a slower clearance. The safety of the two long-acting G-CSF was similar and no serious adverse events (AEs) or clinically significant alterations in laboratory parameters occurred in both studies; tolerability of lipegfilgrastim was consistent with data of pegfilgrastim reported in healthy subjects. ${ }^{51}$

Efficacy (Table 1) and safety of lipegfilgrastim in reducing the duration of CIN and the incidence of FN were tested in Phase II and Phase III trials. 
Table I Efficacy of lipegfilgrastim in randomized trials

\begin{tabular}{|c|c|c|c|c|c|c|c|c|}
\hline \multirow{3}{*}{$\begin{array}{l}\text { Author, } \\
\text { year } \\
\text { Buchner } \\
\text { et al, 201452 }\end{array}$} & \multirow{2}{*}{$\begin{array}{l}\begin{array}{l}\text { Drug (number of } \\
\text { patients) }\end{array} \\
\text { Lipegfilgrastim } 3 \mathrm{mg}(\mathrm{n}=53)\end{array}$} & \multirow{3}{*}{$\begin{array}{l}\begin{array}{l}\text { Tumor, } \\
\text { type }\end{array} \\
\text { High risk }\end{array}$} & \multicolumn{4}{|c|}{ Incidence of severe neutropenia (\%) } & \multicolumn{2}{|c|}{ Mean DSN (days) } \\
\hline & & & Cycle I & Cycle 2 & Cycle 3 & Cycle 4 & Cycle I & Cycle 2 \\
\hline & Lipegfilgrastim $4.5 \mathrm{mg}(\mathrm{n}=5 \mathrm{I})$ & & 56.60 & 20.75 & 18.87 & $|7.3|$ & 1.08 & 0.32 \\
\hline & Lipegfilgrastim 6 mg $(n=50)$ & & 50.98 & $7.84^{\mathrm{c}}$ & $6.0^{\mathrm{a}}$ & $8.33^{b}$ & 0.84 & $0.14^{\mathrm{a}}$ \\
\hline & Pegfilgrastim 6 mg $(n=54)$ & & 38.0 & $18.0^{\mathrm{b}}$ & $10.0^{\mathrm{b}}$ & $8.0^{\mathrm{b}}$ & 0.76 & $0.18^{\mathrm{b}}$ \\
\hline & & & 53.70 & 33.96 & 24.53 & 26.42 & 0.87 & 0.41 \\
\hline Bondarenko & Lipegfilgrastim 6 mg $(n=10 I)$ & High risk & Cycle I & Cycle 2 & Cycle 3 & Cycle 4 & Cycle I & Cycle 2 \\
\hline et al, $2013^{54}$ & Pegfilgrastim $6 \mathrm{mg}(\mathrm{n}=10 \mathrm{I})$ & breast cancer & 43.6 & 8.5 & 8.6 & 12.2 & 0.7 & 0.1 \\
\hline & & & 51.1 & 21.5 & 12.1 & 12.1 & 0.8 & 0.3 \\
\hline & & & $(P=N S)$ & $(P=0.0 \mid 30)$ & $(P=\mathrm{NS})$ & $(P=N S)$ & $(P=\mathrm{NS})$ & $(P=N S)$ \\
\hline Volovat & Lipegfilgrastim 6 mg $(n=250)$ & Non-small cell & Cycle I & Cycle 2 & Cycle 3 & Cycle 4 & Cycle I & Cycle 2 \\
\hline et al, $2015^{56}$ & Placebo $(n=125)$ & lung cancer & 32.1 & 16.7 & 13.8 & 14.8 & 0.6 & 0.3 \\
\hline & & & 59.2 & 52.4 & 51.1 & 55.6 & 2.3 & 2.2 \\
\hline & & & $(P<0.000 \mathrm{I})$ & $(P<0.000 \mathrm{I})$ & $(P<0.000 \mathrm{I})$ & $(P<0.000 \mathrm{I})$ & $(P<0.000 \mathrm{I})$ & $(P<0.000 \mathrm{I})$ \\
\hline
\end{tabular}

Notes: ${ }^{a} P \leq 0.01$ versus pegfilgrastim; ${ }^{b} P \leq 0.05$ versus pegfilgrastim; ${ }^{c} P \leq 0.00$ I versus pegfilgrastim.

Abbreviations: ANC, absolute neutrophil count; DSN, duration of severe neutropenia; FN, febrile neutropenia; NS, not significant.

In a Phase II, randomized, double-blind, dose-finding trial 208 chemotherapy-naïve patients with high-risk stage II, III, or IV breast cancer were randomized 1:1:1:1 to receive lipegfilgrastim at $3,4.5$, and $6 \mathrm{mg}$ or pegfilgrastim at $6 \mathrm{mg}$ subcutaneously on day 2 of each chemotherapy cycle (doxorubicin/docetaxel on day 1 for four 3-week cycles). ${ }^{52,53}$ The mean duration of severe neutropenia (DSN) in cycle 1 (primary endpoint) decreased by increasing lipegfilgrastim doses, with the most effective dose being $6 \mathrm{mg}$, without significant differences between treatment groups. In addition, lipegfilgrastim at $6 \mathrm{mg}$ had comparable efficacy with pegfilgrastim at the same dose, because mean DSN after the first cycle was 0.76 days in the lipegfilgrastim $6 \mathrm{mg}$ arm and 0.87 days in the pegfilgrastim $6 \mathrm{mg}$ arm $(P=$ not significant [NS]). In cycles $2-4$, the mean DSN was shorter than cycle 1 in all treatment groups and was significantly shorter in the lipegfilgrastim $6 \mathrm{mg}$ arm than in pegfilgrastim arm; furthermore, the incidence of severe neutropenia was lower in the lipegfilgrastim groups compared with the pegfilgrastim group for each chemotherapy cycle. In all cycles, incidence of severe neutropenia was lower with lipegfilgrastim at the doses of 4.5 and $6 \mathrm{mg}$ than lipegfilgrastim at $3 \mathrm{mg}$ and pegfilgrastim, and also significantly lower than pegfilgrastim at cycles 2,3 , and $4(P<0.05)$. The percentage of patients who experienced severe neutropenia in cycle 1 was higher in the lipegfilgrastim $4.5 \mathrm{mg}$ arm than in lipegfilgrastim $6 \mathrm{mg}$ arm (50.98\% versus $38 \%, P=\mathrm{NS}$ ). Lipegfilgrastim $6 \mathrm{mg}$ was the only dose associated with a significantly higher ANC at nadir $(P \leq 0.05)$ and with a shorter ANC recovery time $(P<0.05)$ versus pegfilgrastim for all chemotherapy cycles. Only one patient in the pegfilgrastim group experienced FN in cycle 1. FN was observed in two (3.9\%) $4.5 \mathrm{mg}$ lipegfilgrastim, three (6.0\%) $6 \mathrm{mg}$ lipegfilgrastim, and two (3.7\%) pegfilgrastim patients. No mortality related to FN was reported. AEs, whose frequency decreased with each chemotherapy cycle, were similar among treatment arms, and no difference in the three doses of lipegfilgrastim was reported. As expected, the vast majority of the AEs was due to chemotherapy regimen. Only $1.9 \%$ of patients experienced AEs leading to G-CSF discontinuation, mainly for withdrawal of informed consent. In particular, bone-pain-related symptoms (bone pain, myalgia, arthralgia, and back pain) occurred in $4.3 \%-19.2 \%$ of patients without significant differences in the four arms. Thus, this Phase II trial established that lipegfilgrastim $6 \mathrm{mg}$ is the optimal dose for breast cancer patients receiving chemotherapy, and is at least equivalent to pegfilgrastim at a standard dose of $6 \mathrm{mg}$.

Non-inferiority of lipegfilgrastim versus pegfilgrastim was demonstrated in a multicenter, Phase III, randomized, double-blind trial. ${ }^{54}$ High-risk stage II, III, and IV breast cancer patients receiving chemotherapy (doxorubicin/docetaxel) were randomized to receive either $6 \mathrm{mg}$ lipegfilgrastim $(n=101)$ or $6 \mathrm{mg}$ pegfilgrastim $(\mathrm{n}=101)$ on day 2 of each 21-day cycle (four cycles maximum). Mean DSN in cycle 1, that was the primary efficacy endpoint, was similar in both arms ( 0.7 days for lipegfilgrastim and 0.8 days for pegfilgrastim, $P=0.126$ ). The mean DSN was shorter in cycles $2-4$ than in cycle 1 , and no statistically significant difference was observed in DSN between the two groups in cycles 2-4. There was also no statistically significant difference in the incidence of FN in cycles 1-4 between the treatment groups and no mortality related to FN was reported. Severe neutropenia, mostly occurring after the first cycle (43.6\% lipegfilgrastim versus $51.1 \%$ pegfilgrastim, $P=0.3409$ ), was observed with no 


\begin{tabular}{|c|c|c|c|c|c|c|c|c|c|}
\hline \multirow[b]{2}{*}{ Cycle 3} & \multirow[b]{2}{*}{ Cycle 4} & \multicolumn{4}{|c|}{ Incidence of FN (\%) } & \multicolumn{4}{|c|}{ Mean time to ANC recovery (days) } \\
\hline & & \multicolumn{4}{|c|}{ All cycles } & Cycle I & \multicolumn{3}{|c|}{ Other cycles not reported } \\
\hline 0.30 & $0.23^{b}$ & 0 & & & & 7.32 & & & \\
\hline 0.20 & $0.22^{\mathrm{b}}$ & 3.9 & & & & 6.10 & & & \\
\hline $0.12^{\mathrm{b}}$ & $0.12^{\mathrm{a}}$ & 6.0 & & & & $5.80^{\mathrm{b}}$ & & & \\
\hline 0.35 & 0.48 & 3.7 & & & & 7.44 & & & \\
\hline Cycle 3 & Cycle 4 & No statist & difference & cycles I-4 & & Cycle I & Cycle 2 & Cycle 3 & Cycle 4 \\
\hline 0.1 & 0.2 & & & & & 5.9 & 3.6 & 3.9 & 3.3 \\
\hline 0.2 & 0.2 & & & & & 7.4 & 5.3 & 5.1 & 4.3 \\
\hline$(P=N S)$ & $(P=\mathrm{NS})$ & & & & & $(P=0.0026)$ & $(P=0.0082)$ & $(P=0.0332)$ & $(P=\mathrm{NS})$ \\
\hline Cycle 3 & Cycle 4 & Cycle I & Cycle 2 & Cycle 3 & Cycle 4 & Cycle I & Cycle 2 & Cycle 3 & Cycle 4 \\
\hline 0.4 & 0.5 & 2.4 & 0.5 & 0.5 & 1.2 & 6.8 & 5.6 & 6.0 & 5.4 \\
\hline 2.0 & 2.3 & 5.6 & 0 & 1.1 & 2.5 & 13.0 & 13.8 & 13.7 & 14.0 \\
\hline$(P<0.000 \mathrm{I})$ & $(P<0.000 \mathrm{I})$ & $(P=\mathrm{NS})$ & $(P=\mathrm{NS})$ & $(P=\mathrm{NS})$ & $(P=\mathrm{NS})$ & $(P<0.000 \mathrm{I})$ & $(P<0.000 \mathrm{I})$ & $(P<0.000 \mathrm{I})$ & $(P<0.000 I)$ \\
\hline
\end{tabular}

statistically significant difference in incidence in cycles 1,3 , and 4 , whereas, in cycle 2 , the incidence of severe neutropenia in lipegfilgrastim and pegfilgrastim groups was $8.5 \%$ and $21.5 \%$, respectively $(P=0.0130)$. The majority of patients in both groups received chemotherapy as scheduled, with mean percentage of doxorubicin and docetaxel administered reaching more than $98 \%$ in each cycle. In lipegfilgrastim group, 31 patients received delayed chemotherapy treatment and no dose omissions or reductions in cycles 2-4; in pegfilgrastim group, 36 patients received delayed chemotherapy treatment, and eight patients had dose omissions or reductions in cycles 2-4. Reported toxicities were similar in two treatment arms. Again, most AEs were due to complications of chemotherapy or to the primary disease, and occurred with no statistically significant difference in two groups. Bone-pain-related symptoms, including arthralgia, back pain, bone pain, neck pain, myalgia, or other musculoskeletal symptoms, were the most common AEs observed in the study and were reported in $24(23.8 \%)$ patients in the lipegfilgrastim group and 17 (16.8\%) patients in the pegfilgrastim group, with no statistically significant difference.

Evaluations of pharmacokinetics properties of lipegfilgrastim, compared with pegfilgrastim, were also conducted by collecting the blood samples in a subset of patients during cycles 1 and 4. Pharmacokinetics of the two drugs were generally similar, the only difference being that lipegfilgrastim had almost $50 \%$ higher $\mathrm{AUC}_{0 \text {-tlast }}$ and $\mathrm{AUC}_{0-\infty}$ in cycle 1 .

The incidence of bone-pain-related symptoms in patients treated with lipegfilgrastim was assessed in a post hoc analysis of the two randomized studies which compared $6 \mathrm{mg}$ lipegfilgrastim with $6 \mathrm{mg}$ pegfilgrastim in patients with breast cancer receiving chemotherapy. ${ }^{55}$ The analysis of the data from 306 patients (lipegfilgrastim, $n=151$; pegfilgrastim, $\mathrm{n}=155$ ) showed that the number of patients who experienced bone-pain-related treatment-emergent AEs was similar in the two groups (25.2\% versus $21.9 \%$, respectively); likewise, the number of patients treated with lipegfilgrastim who had bone-pain-related treatment-emergent adverse drug reactions was compared with that of patients treated with pegfilgrastim (18.5\% versus $16.8 \%$, respectively).

The results of another Phase III, double-blind, randomized trial aimed to demonstrate the superiority of lipefilgrastim versus placebo in adults with non-small cell lung receiving chemotherapy (cisplatin and etoposide), were recently published. ${ }^{56}$ The study included 375 patients (6 mg lipegfilgrastim, $n=250$; placebo, $n=125$ ) because of the control arm with placebo, patients with individual high risk for FN were excluded. Study drug was administered 24 hours after chemotherapy (day 4) of a 21-day cycle for four cycles.

Incidence of FN in cycle 1 was lower in the lipegfilgrastim group (2.4\%) compared with placebo group (5.6\%), without, however, a statistically significant difference, thus failing the primary endpoint; this probably happened because the chemotherapy regimen at the doses used in the study, has a risk of $\mathrm{FN}<20 \%$, whereas patients with individual high risk ( $\geq 20 \%$ ) of FN were excluded.

Lipegfilgrastim group had significantly shorter DSN in cycle 1 as well as in cycles 2,3 , and 4 , compared with the placebo group. Similarly, the incidence of severe neutropenia was significantly lower in patients receiving lipegfilgrastim, overall and after each cycle, compared with patients receiving placebo. Mean ANC nadir was lowest in cycle 1 and significantly higher for lipegfilgrastim group than for the placebo one. In addition, the mean time to ANC recovery from ANC nadir was 
significantly shorter in the lipegfilgrastim versus placebo in each cycle. Chemotherapy delays were significantly lower in patients treated with lipegfilgrastim than in patients receiving placebo (cycle 2: $28.5 \%$ versus $65.1 \%$; cycle $3: 42.1 \%$ versus $66.3 \%$; cycle 4: $40.4 \%$ versus $75.3 \%$, respectively; all $P \leq 0.0001$ ).

No significant difference in incidence of AEs was observed between the two study groups. Bone-pain-related symptoms were mild or moderate and were reported in lipegfilgrastim group and placebo group in $8.5 \%$ and $6.4 \%$, respectively. Discontinuation from the study was not different between the two groups $(23.0 \%$ lipegfilgrastim group, $26.4 \%$ placebo group).

Recently, the results of the interim analysis of a noninterventional study on the use of lipegfilgrastim on the prophylaxis of CIN were presented.$^{57}$ The study was designed to assess the efficacy and safety of lipegfilgrastim in reducing severe neutropenia and FN in real-life conditions at 80 oncology practices across Germany. The analysis included 224 patients who had completed at least one cycle of chemotherapy with lipegfilgrastim support. The main neoplasia types were breast cancer (46.0\%), lung cancer (13.4\%), and nonHodgkin lymphoma (10.7\%). The FN risk was assessed by investigators: $45.5 \%$ of patients had a high $\mathrm{FN}$ risk $(>20 \%)$, $50.4 \%$, and $3.1 \%$ were in medium-risk (10-20\%) and low-risk $(<10 \%)$, respectively. Lipegfilgrastim was used as primary prophylaxis in $67.0 \%$ of patients, as secondary prophylaxis in $15.2 \%$ and with therapeutic intent in $17.4 \%$. During the first cycle $3(1.3 \%)$, patients developed FN (data are missing for $4.9 \%$ ). No FN was observed when lipegfilgrastim was administered as primary prophylaxis, whereas $\mathrm{FN}$ was observed in one $(2.9 \%)$ patient who received lipegfilgrastim as secondary prophylaxis and in two (5.1\%) patients who received lipegfilgrastim with therapeutic intent. In the subgroup of patients with breast cancer, no FN was observed in patients in primary prophylaxis or with therapeutic intent during the first cycle of chemotherapy, whereas 1 (7.1\%) patient developed FN during secondary prophylaxis. Furthermore, two patients who had been receiving primary prophylaxis, and one patient who had been receiving secondary prophylaxis, had severe neutropenia during the first cycle. Lipegfilgrastim was well tolerated; bone pain, musculoskeletal/connective tissue disorders, myalgia, and arthralgia were not severe (grade 1/2) and were observed in $2.7 \%, 1.3 \%, 0.4 \%$, and $0.4 \%$ of patients, respectively.

\section{Conclusion}

Some years ago, the usage of the pegylation strategy in the synthesis of rG-CSFs enabled the production of pegfilgrastim, which had the same efficacy of a daily G-CSF with a unique administration per-cycle. Lipegfilgrastim is a second-generation, long-acting, once-per-cycle G-CSF, developed to reduce the DSN and the incidence of FN in cancer patients receiving myelosuppressive anticancer drugs.

By the results of the few randomized trials available at the moment, lipegfilgrastim has shown to be equivalent to pegfilgrastim in the management of CIN, at least in the setting of breast cancer and superior to placebo in that of lung cancer. Furthermore, lipegfilgrastim seems to be well tolerated and to have a similar safety profile of pegfilgrastim.

Lipegfilgrastim chemical structure and its pharmacokinetic and pharmacodynamic properties may explain some differences observed in the randomized trials when compared with pegfilgrastim.

To the best of our knowledge, neither consistent data about the efficacy of lipegfilgrastim in patients undergoing chemotherapy for hematological malignancies nor data in hematopoietic stem cells transplant setting have been published so far.

In conclusion, lipegfilgrastim is a promising molecule, alternative to pegfilgrastim, which can be used to manage neutropenia in patients undergoing chemotherapy when a long-acting G-CSF is considered the best choice.

\section{Disclosure}

The authors report no conflicts of interest in this work.

\section{References}

1. Lyman GH, Kuderer NM. Epidemiology of febrile neutropenia. Support Cancer Ther. 2003;1(1):23-35.

2. Crawford J, Dale DC, Lyman GH. Chemotherapy-induced neutropenia: risks, consequences, and new directions for its management. Cancer. 2004;100(2):228-237.

3. de Naurois J, Novitzky-Basso I, Gill MJ, et al. ESMO Guidelines Working Group. Management of febrile neutropenia: ESMO clinical practice guidelines. Ann Oncol. 2010;21(Suppl 5):v252-v256.

4. Common Terminology Criteria for Adverse Advents v3.0 (CTCAE) [Internet]. Available from: http://ctep.cancer.gov/protocolDevelopment/ electronic_applications/docs/ctcaev3.pdf. Accessed August 13, 2015.

5. Nesher L, Rolston KV. The current spectrum of infection in cancer patients with chemotherapy related neutropenia. Infection. 2014;42(1):5-13.

6. Kuderer NM, Dale DC, Crawford J, Cosler LE, Lyman GH. Mortality, morbidity, and cost associated with febrile neutropenia in adult cancer patients. Cancer. 2006;106(10):2258-2266.

7. Pfeil AM, Allcott K, Pettengell R, von Minckwitz G, Schwenkglenks M, Szabo Z. Efficacy, effectiveness and safety of long-acting granulocyte colony-stimulating factors for prophylaxis of chemotherapy-induced neutropenia in patients with cancer: a systematic review. Support Care Cancer. 2015;23(2):525-545.

8. NCCN Guidelines ${ }^{\circledR}$ : Myeloid Growth Factors. Version 2.2014. Available from: http://www.nccn.org/professionals/physician_gls/f_guidelines. asp\#supportive. Accessed August 13, 2015.

9. Aapro MS, Bohlius J, Cameron DA, et al; for European Organisation for Research and Treatment of Cancer. 2010 update of EORTC guidelines for the use of granulocyte-colony stimulating factor to reduce the incidence of chemotherapy-induced febrile neutropenia in adult patients with lymphoproliferative disorders and solid tumours. Eur J Cancer. 2011;47(1):8-32. 
10. Martín M, Seguí MA, Antón A, et al; for GEICAM 9805 Investigators. Adjuvant docetaxel for high-risk, node-negative breast cancer. $N$ Engl J Med. 2010;363(23):2200-2210.

11. Coiffier B, Lepage E, Briere J, et al. CHOP chemotherapy plus rituximab compared with $\mathrm{CHOP}$ alone in elderly patients with diffuse large-B-cell lymphoma. N Engl J Med. 2002;346(4):235-242.

12. Gregory SA, Trümper L. Chemotherapy dose intensity in non-Hodgkin's lymphoma: is dose intensity an emerging paradigm for better outcomes? Ann Oncol. 2005;16(9):1413-1424.

13. Tjan-Heijnen VC, Wagener DJ, Postmus PE. An analysis of chemotherapy dose and dose-intensity in small-cell lung cancer: lessons to be drawn. Ann Oncol. 2002;13(10):1519-1530.

14. Lyman $\mathrm{GH}$, Lyman $\mathrm{CH}$, Agboola O. Risk models for predicting chemotherapy-induced neutropenia. Oncologist. 2005;10(6):427-437.

15. Chrischilles E, Delgado DJ, Stolshek BS, Lawless G, Fridman M, Carter WB. Impact of age and colony-stimulating factor use on hospital length of stay for febrile neutropenia in CHOP-treated non-Hodgkin's lymphoma. Cancer Control. 2002;9(3):203-211.

16. Shayne M, Culakova E, Poniewierski MS, et al. Dose intensity and hematologic toxicity in older cancer patients receiving systemic chemotherapy. Cancer. 2007;110(7):1611-1620.

17. Lyman GH, Kuderer NM, Crawford J, et al. Predicting individual risk of neutropenic complications in patients receiving cancer chemotherapy Cancer. 2011;117(9):1917-1927.

18. Aslani A, Smith RC, Allen BJ, Pavlakis N, Levi JA. The predictive value of body protein for chemotherapy-induced toxicity. Cancer. 2000; 88(4):796-803.

19. Moreau M, Klastersky J, Schwarzbold A, et al. A general chemotherapy myelotoxicity score to predict febrile neutropenia in hematological malignancies. Ann Oncol. 2009;20(3):513-519.

20. Jenkins P, Freeman S. Pretreatment haematological laboratory values predict for excessive myelosuppression in patients receiving adjuvan FEC chemotherapy for breast cancer. Ann Oncol. 2009;20(1):34-40.

21. Lyman GH. Impact of chemotherapy dose intensity on cancer patient outcomes. J Natl Compr Canc Netw. 2009;7(1):99-108.

22. Bosly A, Bron D, Van Hoof A, et al. Achievement of optimal average relative dose intensity and correlation with survival in diffuse large B-cell lymphoma patients treated with CHOP. Ann Hematol. 2008 87(4):277-283.

23. Chirivella I, Bermejo B, Insa A, et al. Optimal delivery of anthracyclinebased chemotherapy in the adjuvant setting improves outcome of breast cancer patients. Breast Cancer Res Treat. 2009;114(3):479-484.

24. Radosavljevic D, Golubicic I, Gavrilovic D, Kezic I, Jelic S. Do the time to chemotherapy response and the dose intensity have an impact on patient outcome in advanced non-small cell lung cancer? J BUON. 2009;14(2):203-209.

25. Trillet-Lenoir V, Green J, Manegold C, et al. Recombinant granulocyte colony stimulating factor reduces the infectious complications of cytotoxic chemotherapy. Eur J Cancer. 1993;29A(3):319-324.

26. Smith TJ, Bohlke K, Lyman GH, et al. Recommendations for the use of WBC growth factors: American Society of Clinical Oncology Clinical Practice Guideline Update. J Clin Oncol. 2015;33(28):3199-3212.

27. Crawford J, Ozer H, Stoller R, et al. Reduction by granulocyte colony-stimulating factor of fever and neutropenia induced by chemotherapy in patients with small-cell lung cancer. $N$ Engl J Med. 1991; 325(3): 164-170

28. Heil G, Hoelzer D, Sanz MA, et al. A randomized, double-blind, placebo-controlled, phase III study of filgrastim in remission induction and consolidation therapy for adults with de novo acute myeloid leukemia. The International Acute Myeloid Leukemia Study Group. Blood. 1997;90(12):4710-4718.

29. Holloway CJ. Applications of recombinant DNA technology in the production of glycosylated recombinant human granulocyte colony stimulating factor. Eur J Cancer. 1994;30A(Suppl 3):s2-s6.

30. Nissen C. Glycosylation of recombinant human granulocyte colony stimulating factor: implications for stability and potency. Eur J Cancer 1994;30A(Suppl 3):s12-s14.
31. Pedrazzoli P, Gibelli N, Pavesi L, et al. Effects of glycosylated and non-glycosylated G-CSFs, alone and in combination with other cytokines, on the growth of human progenitor cells. Anticancer Res. 1996; 16(4A):1781-1785.

32. Sourgens H, Lefrère F. A systematic review of available clinical evidence - filgrastim compared with lenograstim. Int J Clin Pharmacol Ther. 2011;49(8):510-518.

33. Hosing C. Hematopoietic stem cell mobilization with G-CSF. Methods Mol Biol. 2012;904:37-47.

34. Grabowski H, Guha R, Salgado M. Biosimilar competition: lessons from Europe. Nat Rev Drug Discov. 2014;13(2):99-100.

35. Zündorf I, Dingermann T. PEGylation - a well-proven strategy for the improvement of recombinant drugs. Pharmazie. 2014; 69(5):323-326.

36. Lord BI, Woolford LB, Molineux G. Kinetics of neutrophil production in normal and neutropenic animals during the response to filgrastim (r-metHu G-CSF) or filgrastim SD/01 (PEG-r-metHu G-CSF). Clin Cancer Res. 2001;7(7):2085-2090.

37. Hoggatt J, Pelus LM. New G-CSF agonists for neutropenia therapy. Expert Opin Invest Drugs. 2014;23(1):21-35.

38. Green MD, Koelbl H, Baselga J, et al. For International Pegfilgrastim 749 Study Group. A randomized double-blind multicenter phase III study of fixed-dose single-administration pegfilgrastim versus daily filgrastim in patients receiving myelosuppressive chemotherapy. Ann Oncol. 2003;14(1):29-35.

39. Morishita M, Leonard RC. Pegfilgrastim; a neutrophil mediated granulocyte colony stimulating factor-expanding uses in cancer chemotherapy. Expert Opin Biol Ther. 2008;8(7):993-1001.

40. George S, Yunus F, Case D, et al. Fixed-dose pegfilgrastim is safe and allows neutrophil recovery in patients with non-Hodgkin's lymphoma. Leuk Lymphoma. 2003;44(10):1691-1696.

41. Brusamolino E, Rusconi C, Montalbetti L, et al. Dose-dense R-CHOP-14 supported by pegfilgrastim in patients with diffuse large B-cell lymphoma: a phase II study of feasibility and toxicity. Haematologica. 2006;91(4):496-502.

42. Musto P, Scalzulli PR, Terruzzi E, et al. Peg-filgrastim versus filgrastim after autologous stem cell transplantation: case-control study in patients with multiple myeloma and review of the literature. Leuk Res. 2007;31(11):1487-1493.

43. Kim MG, Han N, Lee EK, Kim T. Pegfilgrastim vs filgrastim in PBSC mobilization for autologous hematopoietic SCT: a systematic review and meta-analysis. Bone Marrow Transplant. 2015;50(4): 523-530.

44. Lonquex ${ }^{\circledR}$. Summary of Product Characteristics. London: European Medicines Agency; 2013.

45. Mahlert F, Schmidt K, Allgaier H, Liu P, Muller U, Shen WD. Rational development of lipegfilgrastim, a novel long-acting granulocyte colonystimulating factor, using glycopegylation technology [abstract]. Blood. 2013;122(21):4853.

46. Scheckermann C, Schmidt K, Abdolzade-Bavil A, et al. Lipegfilgrastim: a long-acting, once-per-cycle, glycopegylated recombinant human filgrastim [abstract]. J Clin Oncol. 2013;e13548.

47. Ratti M, Tomasello G. Lipegfilgrastim for the prophylaxis and treatment of chemotherapy-induced neutropenia. Expert Rev Clin Pharmacol. 2015;8(1):15-24.

48. Abdolzade-Bavil A, Cooksey BA, Scheckermann C, et al. Pegylated versus glycopegylated G-CSFs and their biochemical and physiological properties [abstract]. Blood. 2013;122(21):4851.

49. Abdolzade-Bavil A, von Kerczek A, Cooksey BA, et al. Differential sensitivity of lipegfilgrastim and pegfilgrastim to neutrophil elastase correlates with differences in clinical pharmacokinetic profile. $J$ Clin Pharmacol. 2015. Epub 2015 Jun 23.

50. Buchner A, Lammerich A, Abdolzade-Bavil A, Müller U, Bias P. Lipegfilgrastim: pharmacodynamics and pharmacokinetics for body-weight-adjusted and $6 \mathrm{mg}$ fixed doses in two randomized studies in healthy volunteers. Curr Med Res Opin. 2014;30(12): $2523-2533$. 
51. Kroschinsky F, Hölig K, Poppe-Thiede K, et al. Single-dose pegfilgrastim for the mobilization of allogeneic $\mathrm{CD} 34^{+}$peripheral blood progenitor cells in healthy family and unrelated donors. Haematologica. 2005;90(12):1665-1671.

52. Buchner A, Elsässer R, Bias P. A randomized, double-blind, active control, multicenter, dose-finding study of lipegfilgrastim (XM22) in breast cancer patients receiving myelosuppressive therapy. Breast Cancer Res Treat. 2014;148(1):107-116.

53. Gladkov OA, Buchner A, Bias P, Müller U, Elsässer R. Chemotherapyassociated treatment burden in breast cancer patients receiving lipegfilgrastim or pegfilgrastim: secondary efficacy data from a phase III study. Support Care Cancer. Epub 2015 Jun 20.

54. Bondarenko I, Gladkov OA, Elsaesser R, Buchner A, Bias P. Efficacy and safety of lipegfilgrastim versus pegfilgrastim: a randomized, multicenter, active-control phase 3 trial in patients with breast cancer receiving doxorubicin/docetaxel chemotherapy. BMC Cancer. 2013;13:386.
55. Bondarenko IM, Bias P, Buchner A. Incidence of bone pain in patients with breast cancer treated with lipegfilgrastim or pegfilgrastim: an integrated analysis from phase II and III studies. Support Care Cancer. 2015. Epub 2015 May 30.

56. Volovat C, Bondarenko IM, Gladkov OA, et al. Phase III, randomized, double-blind, placebo-controlled, multicenter study of lipegfilgrastim in patients with non-small cell lung cancer receiving myelosuppressive therapy. Springerplus. July 3, 2015;4:316.

57. Kurbacher CM, Fietz T, Diel IJ, et al. NADIR: a non-interventional study on the prophylaxis of chemotherapy-induced neutropenia using lipegfilgrastim - first interim analysis. Oncol Res Treat. 2015; 38(5):221-229.

\section{Publish your work in this journal}

Biologics: Targets \& Therapy is an international, peer-reviewed journal focusing on the patho-physiological rationale for and clinical application of Biologic agents in the management of autoimmune diseases, cancers or other pathologies where a molecular target can be identified. This journal is indexed on PubMed Central, CAS, EMBase, Scopus

\section{Dovepress}

and the Elsevier Bibliographic databases. The manuscript management system is completely online and includes a very quick and fair peerreview system, which is all easy to use. Visit http://www.dovepress. com/testimonials.php to read real quotes from published authors. 